\title{
ist \\ Epigénesis y preformacionismo: radiografía de una antinomía inconclusa
}

\author{
Davide Vegchi \\ Isaac HERNÁNDEZ
}

\begin{abstract}
$\ddot{\ddot{\circ}}$
RESUMEN

El desarrollo embriológico es un fenómeno que ha inspirado la especulación filosófica desde temprano en la historia del pensamiento. Desde los tiempos de Aristóteles dos modelos conceptuales antitéticos se han utilizado tradicionalmente para comprender la embriogénesis: o el embrión posee ya una forma o estructura, o ésta se forma de nuevo en cada generación. Nuestro objetivo en este artículo es mostrar que el contraste entre la posición preformacionista y epigenética persiste a pesar de los formidables avances teóricos y experimentales de la biología del desarrollo contemporánea. El preformacionismo y la epigénesis han perfeccionado constantemente sus posiciones en el curso de la historia con el fin de responder a los retos conceptuales de la época. Este continuo proceso de transformación ha dado lugar a una convergencia parcial entre las dos posiciones. Sin embargo, vamos a argumentar que, a pesar de los esfuerzos por conciliar ambas posturas, esta antinomia, que se erige como una de las más fundamentales de la biología, no será fácil de superar.
\end{abstract}

Palabras-clave • Embrión. Preformación. Epigénesis. Determinante. Campo morfogenético. Morfogen. Mosaicismo. Regulación.

\section{INTRODUGIENDO LA ANTINOMIA:}

\section{UNA BREVE HISTORIA DEL DEBATE PREFORMACIONISMO-EPIGÉNESIS}

El fenómeno del desarrollo morfológico de un ser vivo ha sido un tema que ha acaparado la atención desde los primeros tiempos del pensamiento. Así, no es extraño que Aristóteles, quién probablemente encarnara al primer embriólogo de la historia, se posicionara frente al fenómeno bajo dos vías hipotéticas aparentemente irreconciliables: o el desarrollo se explica por un orden preexistente en el embrión, o este orden es formado en cada generación desde cero. Esta inquietud potenciaría dos modos de entender la emergencia de la forma biológica que estarán entrelazados hasta los tiempos actuales.

La primera hipótesis, el preformacionismo, por mucho tiempo concibió el desarrollo como el desempaquetamiento de una estructura ya existente, asumiendo por tanto que la organización del ser viviente estaba ya presente en el embrión en miniatura 
(el homúnculo de Nicolaas Hartsoeker proporciona una llamativa representación de esta postura). Así, el compromiso de localizar la forma orgánica ha sido desde siempre la marca distintiva de la tesis preformacionista. Bajo su forma más extrema, esta tesis se compromete con la preexistencia, dentro del óvulo o espermatozoide, de una entidad perfectamente estructurada, cuyo origen remonta a un acto creador en el principio de los tiempos. Entonces, más que de desarrollo, se trata, en todo caso, del crecimiento de un orden que está encapsulado (localizado) en las estructuras sexuales.

Por otro lado, la hipótesis de la epigénesis concibe el fenómeno del desarrollo como un proceso de ordenamiento de la materia embrionaria, inicialmente amorfa, hacia una forma biológica estructurada. A la inversa del preformacionismo, el desarrollo no se piensa sólo como crecimiento, sino como un proceso de estructuración del embrión amorfo bajo principios orgánicos de organización.

Si por un lado el preformacionismo estuvo naturalmente ligado a un marco creacionista, la epigénesis estuvo ligada naturalmente a algunas formas de animismo y vitalismo. En efecto, si asumimos que los principios que gobiernan el proceso del desarrollo embrionario no se explican por la pre-existencia de un orden inmanente, cuyo origen remonta a un gesto original de creación, entonces es necesario explicar cómo el orden orgánico emerge en cada generación. De esta forma, la teoría epigenética se compromete con explicar cómo la materia se desarrolla desde un estado indefinido hacia uno claramente definido bajo principios naturales. Para responder a esto, la postura epigenética a menudo se apoyó en la postulación de un principio vital orgánico que sustenta la emergencia de la forma embrionaria.

Como es de ver, ambas posturas se comprometen con postulados metafísicos que serán elaborados con el paso del tiempo, lo que ha dado forma al debate a través de una estructuración teórica bipolar de apariencia irreconciliable. Entonces, como veremos a lo largo de este artículo, es la reestructuración de estos mismos principios metafísicos lo que ha proporcionado el combustible de este debate hasta la actualidad.

Para establecer un origen del problema en el marco de nuestra exposición, podemos situarnos en el contexto de la modernidad, donde ambas posturas se enfrentaban con virulencia. En aquel momento, si bien el preformacionismo contaba con la simpatía gnoseológica creacionista de la época, la emergencia de la mecánica de Newton vino a fortalecer la postulación de una fuerza vital directriz, cuya analogía con la fuerza gravitacional invisible permitió imaginar su homologo orgánico para regular la embriogénesis (cf. Lenoir, 1989, p. 20-1). Abraham Trembley, en su obra Mémoires pour servir à l'histoire d'un genre de polypes d'eau douce, à bras en forme de cornes (1744), otorgaría un soporte empírico a la epigénesis al demostrar que el pólipo de agua dulce podía regenerar sus tentáculos amputados, justificando el uso de fuerzas orgánicas rectoras de la organización biológica que se constatan por sus efectos regenerativos. El poder 
de regeneración del pólipo dio una pauta general del poder inherente de la materia viva, al considerar que la organización (o reorganización) podía ocurrir en distintos puntos del cuerpo. En efecto, después de la experiencia de Trembley la teoría preformacionista necesitaba ser modificada, pasando de una teoría general de gérmenes ubicados en un sector específico del cuerpo a una teoría de preexistencia de gérmenes también locales.

El preformacionismo tradicional era una tesis cuyo espíritu conservador le impedía concebir los cambios que podría sufrir la forma orgánica a través del tiempo. Por esto mismo tendría complejas dificultades para explicar el parecido de un organismo a ambos progenitores. Si bien el organismo adulto estaría pre-formado en el óvulo de la madre o en el líquido seminal del padre, era imposible no señalar el evidente parecido a ambos progenitores. Esta crítica, que se extendía también hacia la existencia de híbridos - una mula por ejemplo - y a las malformaciones, podía al parecer sólo explicarse por procesos epigenéticos (cf. Hernández, 2012, p. 66-7).

Finalmente, si se considera que los animálculos eran en realidad seres completos con todas sus partes, entonces todas las generaciones de seres debían estar contenidos en el primer ejemplar, en el caso de los humanos, desde "Adán y Eva”, para lo cual estaban obligados a abrazar la tesis metafísica de que Dios dispuso desde el origen de la creación todo lo necesario para que el mundo funcionase por si mismo. Tal acto creador implica la simultánea creación de todos los seres vivos que van a nacer y posiblemente la de muchos otros que jamás nacerán (cf. Norro, 2011, p. 171). Se trata entonces de la afirmación de la existencia de los gérmenes en el origen de los tiempos, un origen tan antiguo como el universo mismo, cuya defensa arrastra necesariamente una inflación de disposiciones metafísicas. De esta forma, el preformacionismo termina violando la navaja de Ockham para sustentar el origen de los gérmenes, pues la aceptación de principios metafísicos para sustentar la permanencia de los gérmenes intactos desde el principio hasta el fin de los tiempos involucra una extrema utilización de tesis infalsificables. Esto último impide la posibilidad de confeccionar sistemas naturales que, como la epigénesis, planteen la posibilidad de explicar los fenómenos vivientes a partir de principios naturales que respondan a una expectativa de carácter más científica.

A finales del siglo xviı y comienzos del siglo xix, las debilidades del preformacionismo tradicional comienzan a hacerse notar, sobre todo cuando los avances en la técnica instrumental habrían proporcionado hallazgos empíricos que permitían documentar con mayor precisión los procesos del desarrollo: la imposibilidad de constatar estructura en las primeras fases del desarrollo inclinó poco a poco la balanza hacia los epigenetistas. Finalmente, la vía epigenética de explicación logra introducirse como una opción válida en las teorías del desarrollo, desplazando parcialmente a la teoría preformacionista tradicional. 


\section{WEISMANN Y LA RE-INVENGIÓN DEL PREFORMAGIONISMO.}

A mediados del siglo xix ya se pensaba que todos los procesos vitales específicos - metabolismo, crecimiento, reproducción y herencia - podían ser reducidos a las actividades que ocurren dentro de ciertas estructuras llamadas células. Consecuentemente, la teoría celular se construyó respecto a tres principios: que todas las plantas y animales están hechos de células, que todas las células surgen de otras células y que las células poseen todos los atributos de la vida (cf. Sapp, 2003, p. 75). La célula, como unidad básica estructural y funcional de la vida, supone que toda célula deriva de otra célula por medio de divisiones funcionales, y así hasta la primera célula huevo llamada embrión. Por tanto, se puede pensar en una correlación causal entre la primera célula embrionaria y el organismo adulto, cuyas funciones vitales serían controladas desde el interior de estas unidades estructurales. Weismann va más lejos al localizar las partículas responsables de la herencia en el núcleo de las células germinales, afirmando que "la naturaleza de la célula está en realidad decidida por elementos del núcleo" (Weismann, 1893, p. 26). La herencia estaría en principio contenida en el plasma germinal de la célula embrión agrupada en series de unidades llamadas determinantes, cada una con propiedades particulares. Las células germinales conservarían en su núcleo todos los determinantes propios de la especie, en cambio las células que forman el soma perderían tal información en el transcurso de las divisiones celulares (cf. Dupont, 2013). Como el embrión parecía contener todo lo necesario para desarrollar el organismo completo, Weismann postularía el proceso del desarrollo embrionario como la distribución progresiva de estos determinantes, los que formarían las diferentes partes del cuerpo a través de la desintegración o división de la información en cada división celular (en analogía con un mosaico). Este esquema traduce el desarrollo como un proceso de pérdida gradual de potencialidades a partir de una célula totipotencial (es decir, el embrión) por medio de divisiones celulares consecutivas, dando origen a un organismo multicelular, cuyos constituyentes son células que perdieron su totipotencialidad, dado que se especializaron. La diferenciación celular es así equivalente a un proceso gradual de pérdida de capacidades de desarrollo.

La hipótesis de Weismann refresca la teoría preformacionista, dado que conceptualiza el desarrollo como un proceso causal unidireccional que parte desde el núcleo de la célula embrión hasta el organismo adulto, sin recurrir a una fuerza vital invisible. Esto permite concebir la morfogénesis como un proceso cerrado y limitado a la actividad del núcleo de las células sin la influencia de variables de otro tipo: “...el destino de las células está determinado por las fuerzas situadas dentro de ellas, y no por influencias externas" (Weismann, 1893, p. 134). Si los determinantes son pensados como "codificadores" de algún tipo de información, entonces esto significa que la información 
endógena otorgada por los determinantes es suficiente para determinar la ontogenia. La hipótesis ontogenética de Weismann prepara el camino para la introducción de una noción fuerte de información en biología. La idea de que el organismo entero está contenido, potencialmente, en un lugar físico y espacialmente definido, equivale a imaginar que los determinantes - una sustancia material que debe estar en el núcleo - opera al modo de un plano arquitectónico cuyas instrucciones son seguidas estrictamente por las demás unidades estructurales. Esto descubre otra ventaja de la hipótesis de Weismann: su facilidad para ser modelada y testeada, lo que permitiría imaginar más tarde la posibilidad de poder "computar" el organismo entero (véase la sección 4).

Pronto la hipótesis del mosaico preformacionista de Weismann ganó soporte empírico a través de los experimentos de Wilhelm Roux con la famosa "aguja caliente". En 1888 Roux tomó embriones de rana en desarrollo temprano y, después de la primera división celular, destruyó una de las células insertando una aguja caliente. Una mitad se desarrollaba acorde al fragmento viable de embrión, tal como debía ocurrir dada la restricción de su información, mientras que la otra mitad simplemente no se desarrollaba. Este experimento proporcionaba evidencia a favor de la hipótesis de Weismann, principalmente porque mostraba que en cada división celular ocurría también una fragmentación de la información hereditaria contenida en el huevo. Sin embargo, cuando en 1892 Hans Driesch intentó repetir los experimentos de Roux siguiendo otro método (en lugar de destruir la célula con una aguja caliente, separó las células por agitación) y con otra especie (en lugar de ranas usó erizos de mar), descubrió que cada célula separada formaba un embrión entero, aunque más pequeño (el fenómeno de escala embrionaria (embryonic scaling). Driesch concluía a favor de la totipotencialidad celular, contradiciendo la hipótesis de Weismann sobre el desarrollo entendido como fenómeno de pérdida de información y partición específica de material hereditario. Más tarde, en 1924, Hans Spemann y Hilde Mangold, a través de experimentos de trasplantes, descubrían que el tejido embrionario poseía un poder "organizador", ya que podía generar una estructura entera y viable en el huésped (también de otra especie), a partir de un fragmento de células trasplantadas (cf. Amundson, 2005; Maienschein, 2005).

\section{EnGUAdRANdo El Debate: LA IMPortancia DE LOS EXPERIMENTOS DE Roux, Driesgh y Mangold-Spemann}

Estos experimentos abrían muchos debates en embriología. En primer lugar, la tesis preformacionista de Weismann choca con el problema, más complejo de lo previsto, de la naturaleza causal del fenómeno de diferenciación celular. Por un lado, la 
postulación de un proceso lineal, determinista y regulado por ciertas entidades químicas localizadas en el núcleo del embrión no podía explicar fácilmente las interacciones causales deslocalizadas que sugieren los experimentos de Driesch, en donde la diferenciación celular parece también estar constreñida por elementos externos al núcleo del embrión. En efecto, los experimentos de Driesch y Mangold-Spemann mostraban que el proceso de diferenciación depende también de la "posición" relativa de la célula en el contexto embrionario:

Driesch describía el embrión de erizo de mar como un 'armonioso sistema equipotencial'. El potencial de una célula para diferenciarse en una parte específica del cuerpo depende de su posición dentro del embrión. Así, Driesch introdujo el concepto de información posicional 75 años antes de ser reintroducido y refinado por Lewis Wolpert (Roth, 2011, p. 256).

Grosso modo, la tesis epigenética de Driesch y Spemann sugería que la diferenciación celular dependía tanto de su posición dentro de un contexto embrionario global de relaciones celulares como de la información que pueda tener cada cuál en si misma. El concepto de información posicional implícito en la teoría del desarrollo de Driesch implica que la información ambiental o contextual (como por ejemplo la interacción entre células embrionarias) puede causar cambios en el estatus final de la célula. Esto contradice una de las ideas centrales de Weismann sobre la morfogénesis entendida como un proceso celular limitado a la actividad del núcleo y cerrado a las influencias externas de cualquier tipo.

En segundo lugar, ese debate tuvo un fuerte impacto en la historia y didáctica de la embriología. Como Lawrence and Levine (2006) lo indican, hasta no hace mucho a los estudiantes de biología del desarrollo se les enseñaba que existen embriones de dos tipos: el mosaico y el regulativo. Los embriones de los animales invertebrados eran pensados tradicionalmente como mosaicos, mientras que los vertebrados eran pensados como auto-regulativos (en conflicto con los experimentos de Driesch y Roux respectivamente). Los embriones del tipo mosaico se consideraban como colecciones rígidas de células con un destino predeterminado y restringido, como lo propuso inicialmente Weismann, mientras que los embriones regulativos se consideraban flexibles y capaces de adaptarse a las interferencias ambientales, tal como tradicionalmente lo proponía la escuela epigenética. Esta dicotomía, sin embargo, se volvió insostenible a medida que aparecía la evidencia experimental, pues esta categorización rígidamente dicotómica nunca salió del plano puramente ideal, dado que, por un lado "el embrión mosaico es una abstracción que no existe" y por otro, "el embrión regulativo probablemente sólo existe en nuestra imaginación” (Lawrence \& Levine, 2006, p. R237). 
En la actualidad, se ha hecho evidente el carácter abstracto e irreal de la caracterización del desarrollo bajo dos modelos separados. En efecto "las interacciones entre las células embrionarias son intrínsecas al proceso regulativo, cuyas interacciones especifican el destino celular. Este tipo de interacción celular ha permitido poner actualmente en primer plano la señalización intercelular" (Lawrence \& Levine, 2006, p. $\left.\mathrm{R}_{2} 3_{7}\right)$. Una interpretación simplificada de la hipótesis de Weismann era que todos los determinantes del proceso de desarrollo son factores nucleares localizables. Por supuesto, hay determinantes ubicados en el óvulo de la madre. Sin embargo, esto no es todo; porque, en última instancia, "en embriones previamente clasificados como de tipo mosaico o regulativo, interacciones multilaterales conducen a una elaboración progresiva. Tanto los determinantes localizados como las moléculas de señalización son agentes en estas interacciones, y todos los tipos de embriones tienen ambos" (Lawrence \& Levine, 2006, p. R239). Por lo tanto, es importante entender cómo las células interactúan de manera coordinada en los procesos del desarrollo. En otros términos: es importante entender la naturaleza de los procesos epigenéticos postulados por Driesch y Spemann.

A pesar de lo anterior, si hacemos una retrospectiva desde la perspectiva contemporánea, una asimetría notable entre estas dos visiones se hace evidente. Los procesos preformacionistas fueron rápidamente entendidos por la genética del desarrollo en términos causales conceptualmente accesibles: los determinantes de Weismann se convertirían en los genes y en los factores de transcripción de hoy. Pero los procesos epigenéticos eran mucho más difíciles de conceptualizar, ya que la comprensión de fenómenos tales como la regeneración de partes y la regulación embrionaria requiere un intento explicativo mucho más sofisticado. El embrión mosaico supuestamente se desarrollaba de acuerdo a un programa, pues cada célula (por ejemplo, un blastómero) sólo genera la parte del embrión que se supone que debe generar desde el principio. Sin embargo, el embrión regulativo debía desarrollarse de acuerdo a ciertas dinámicas causales en gran parte desconocidas. Así, los determinantes postulados por Weismann fueron finalmente reivindicados por la genética del desarrollo y algunas décadas más tarde, la promesa de un análisis causal molecular del proceso del desarrollo fue apoyada por el descubrimiento de los morfógenos. De esta forma, la caracterización concreta de los conceptos de un sistema equipotencial armonioso y organizador, postulados respectivamente por Driesch y Spemann, permaneció esquiva. Así, Driesch (1914) se alineó con la tradición vitalista, postulando una fuerza fundamental responsable de la auto-regulación del embrión, mientras que Spemann optó más bien por una posición inestable con fundamentos holistas y vitalistas (Hamburger, 1999), negando que "el organizador" pueda ser caracterizable únicamente en términos bioquímicos. Su conclusión era que, dado que "el desarrollo embrionario parecía requerir de una forma de 
auto-organización que no se había observado en la materia inerte" (Roth 2011, p. 256), ni la física ni la química serían apropiadas para explicar el complejo proceso de regulación, auto-organización y regeneración que podemos remarcar en sus experimentos.

Si bien es probable que la profesión vitalista de los defensores de la epigénesis no haya contribuido a esparcir con más fuerza la teoría dentro de la comunidad científica, sus contribuciones no serían para nada estériles. La entidad conceptual que postulaban, que nos recuerda a la fuerza vital de inspiración newtoniana postulada por los vitalistas que se oponían a los preformacionistas tradicionales, prepararía el camino para la introducción de una nueva entidad conceptual que buscaba dar aire a la teoría epigenética. Nos referimos al concepto de campo morfogenético; entendido como una clase de plan, o principio de organización, que denotaría la fuente de información adicional necesaria para explicar los resultados de Driesch y Mangold-Spemann.

\section{De LOS GAMPOS MORFOGENÉTICOS A LA EMBRIOLOGÍA COMPUTAGIONAL}

El concepto de campo morfogenético fue introducido por Boveri (1910) y Gurwitsch (1910) para explicar el fenómeno de coordinación entre las células de un tejido. El concepto se volvió una pieza clave en la embriología experimental durante la primera parte del siglo xx, puesto que no era sólo una postulación necesaria para explicar la naturaleza causal involucrada en algunos fenómenos biológicos, sino que también fue el concepto central de una tradición científica (Gestaltunggesetze) que intentaba capturar las reglas de las formas vivientes (cf.Gilbert et al., 1996). El orden espacio-temporal de un organismo en desarrollo es descrito como un campo, en analogía con la teoría del campo electromagnético de la física (cf. Haraway, 1976). Distintas observaciones experimentales parecían indicar la existencia de colectivos particulares de células donde se generaba y regulaba la formación de estructuras definidas - como por ejemplo la formación de extremidades - incluso cuando tales regiones eran trasplantadas en otro lugar o divididas, lo que no impedía la (re)generación completa de la extremidad en cuestión (cf. Huxley \& de Beer, 1934). También cuando algunas células indiferenciadas eran introducidas en alguna región particular, estas se incorporaban organizándose y diferenciándose en armonía con esa región, evidenciando el poder organizador del campo (cf. Spemann, 1938).

A pesar del éxito inicial del concepto de campo morfogenético, este fue abandonado a mediados del siglo pasado. Con el advenimiento de la genética y los desarrollos de la bioquímica, se volvió esencial identificar la naturaleza molecular y causal del campo. Pero los embriólogos de la primera parte del siglo xx carecían de técnicas apropiadas para lograr estos resultados. De esta forma, el concepto de campo quedó experi- 
mentalmente inaccesible durante mucho tiempo, lo que permitió que la genética del desarrollo fuera percibida como la avenida más prometedora para entender los procesos embriogenéticos a nivel bioquímico. ${ }^{\mathbf{1}}$ De esta forma, la molecularización de la genética produce el simultáneo efecto de eclipsar el concepto de campo y de revivir la tradición preformacionista: la estructura latente que determina el proceso de la morfogénesis (la estructura que no podía verse a través de las técnicas microscópicas de los siglos xVII, xviıi y xix, y que Weismann postulaba a través de los determinantes), fue interpretada como el ADN, redefiniendo la morfología como el estudio de los cambios en la expresión genética (cf. Gilbert et al., 1996) y dando luz a una nueva forma de preformacionismo de marco informacional.

En ese sentido, podemos decir que el concepto de gen opaca al concepto campo en la explicación del desarrollo embriológico fundamentalmente por su fecundidad como programa de investigación experimental. De hecho, en sus orígenes, al igual que el concepto de campo, el gen es un recurso heurístico que se constataba por sus efectos regulares en la materia, por lo que podemos decir que estamos frente una dicotomía de métodos. En otros términos, vemos confrontadas dos heurísticas, una reduccionista y otra holista. La heurística reduccionista o reduccionismo instrumental (cf. Falk, 1984), en el caso del gen, se basa en la postulación de unidades últimas indivisibles (una forma de atomismo) que explicarían, una vez combinadas entre sí, la composición cualitativa de un organismo, lo que es igual a decir que el todo es la suma de estas unidades. Mientras que la heurística holista, en el caso del campo, defiende una interpretación relacional del fenómeno, en donde las partes se realizan, o toman su posición, sólo en función de la estructura global, por lo que no existirían niveles de organización biológica primarios.

Como hemos visto en la segunda sección, Weismann ya anticipaba un tipo de reduccionismo instrumental en 1893. Sin embargo, la naturaleza del material hereditario, su localización y la forma en que este estaba codificado no estaban claras, aún cuando él creía que la mayoría de los determinantes estaban localizados en los cromosomas del núcleo. En la primera parte del siglo xx se avanzó en importantes investigaciones para identificar la entidad sub-celular responsable de la herencia. Primero Griffith en 1928, y luego Avery en 1944, establecieron que el ADN era la molécula en cuestión (cf. Amsterdamska, 1993). Mientras tanto, el físico Schrodinger anticipaba una visión informacional contemporánea, denotando a los cromosomas como las estructuras que contienen en "un tipo de código el patrón completo del futuro desarrollo del individuo" (Schrodinger, 1944, p. 20). La existencia de un código implica la existen-

1 Para una revisión sobre la historia conceptual del concepto de campo morfogenético con especial énfasis en las cuestiones relativas a la causalidad del desarrollo, ver Vecchi y Hernández, 2014. 
cia de información codificada de alguna manera. Así, Watson y Crick introducen el término "información" en la genética: "parece probable que la secuencia precisa de las bases es el código que lleva la información genética” (Watson \& Crick 19533, p. 964). Por último, Crick, en 1958, introduce un modelo de especificidad genética en donde el arreglo de las bases nucleicas determina la estructura proteica. Esto se podría considerar como el paso definitivo desde una visión instrumental del gen hacia una noción realista del mismo. Con la llegada del "dogma central" a la biología molecular, los genes se vuelven la única unidad de información biológica. El dogma refuerza la idea de que los genes son especiales por dos razones fundamentales: por un lado, los genes son la única causa del desarrollo, en el sentido de que sólo la información genética "dirige" el desarrollo; y, por otro, los genes son la única entidad estable durante la ontogenia y la filogenia, la unidad fundamental de la fenogénesis y de la herencia. Estas dos hipótesis constituyen la base conceptual del preformacionismo informacional. El modelo informacional de especificidad biológica introducido por Crick fue reforzado con el modelo del operón propuesto por Monod y Jacob en 1961 (cf. Morange, 1998). En este modelo, el genoma se vuelve el único agente activo que controla la ejecución de las instrucciones del programa contenido en él. Así, la regulación del desarrollo se entiende como un despliegue de información decodificada a nivel genético, cuya metáfora nos recuerda al despliegue del homúnculo encapsulado de la tradición preformacionista.

Es en ese contexto que, en 1975, Wolpert y Lewis proponen una variante extrema de preformacionismo informacional:

Una teoría del desarrollo efectivamente nos permitiría computar el organismo adulto a partir de la información genética del huevo. El problema puede ser abordado viendo el huevo como el contenedor de un programa para el desarrollo, y considerando la naturaleza lógica del programa al tratar a las células como autómatas e ignorando los detalles de los mecanismos moleculares (Wolpert \& Lewis, 1975, p. 14).

El primer rasgo interesante de esta posición es el desplazamiento desde una visión preformacionista embrionaria del desarrollo, en donde los determinantes se localizan en el huevo fertilizado, a una visión genética, en donde los determinantes se localizan en el núcleo. Antes de 1975, el propio Wolpert había argumentado a favor del preformacionismo embrionario (cf. Wolpert, 1971). Wolpert propuso perspicaces sugerencias teóricas para fundamentar esa posición, entre ellas el concepto de información posicional y el modelo conceptual de la bandera francesa (French flag model), sin embargo empezó a apoyar el preformacionismo genético por razones que son difíciles de entender (cf. Keller, 2002; Vecchi \& Hernández, 2014). 
La segunda característica fundamental del modelo de Wolpert y Lewis es el computacionalismo. La embriología computacional se basa en la hipótesis de que es posible computar la forma del adulto a partir de la información genética del huevo, es decir, que el huevo posee un programa genético que permite construir un organismo adulto (cf. Rosenberg, 1997). Sus supuestos fundamentales son, primero, que el huevo contiene internamente todos los recursos que el desarrollo necesita para construir un organismo. Segundo, que estos recursos son de origen genético. Tercero, que estos recursos controlan el comportamiento de las células. De este último supuesto se deduce que el comportamiento de las células es redundante en términos causales. El modelo de la morfogénesis de Wolpert y Lewis reduce eficazmente el proceso de regulación al proceso de la expresión génica diferencial, así el concepto de programa de desarrollo fue incluido en la categoría de programa genético y el concepto de información posicional fue subsumido en la categoría de la información genética. Finalmente, el problema de la regulación fue reducido al problema de la diferenciación celular, una idea originalmente propuesta por Weismann (1893).

Lo interesante de la embriología computacional es que todas las principales características del preformacionismo clásico pueden ser identificadas: el huevo contiene un programa genético (es decir, la estructura preformada latente) para el desarrollo que es completo y opera de manera determinista (es decir, es un algoritmo que potencialmente permite el cálculo del organismo adulto, desechando el aporte de cualquier factor no genético). Como es de esperar, muchos principios conceptuales de este modelo son problemáticos, fundamentalmente porque las células se tratan como autómatas. La idea de computar el embrión se basa en una simplificación metodológica según la cual el comportamiento celular está completamente determinado por el ADN ya que, ex hypóthesi, cada célula contiene una lista de reglas que determinan su comportamiento (cf. Wolpert, 1989, p. 8). El concepto original de información posicional introducido por Wolpert contenía dos variables: una informativa y otra interpretativa. Sin embargo, al pensar la interpretación como equivalente al tratamiento de la información genética codificada en la serie de listas preformadas con la que cada célula está supuestamente dotada desde el principio, la variable de interpretación se reduce a la variable de información. De esta forma, las células no harían nada importante durante el desarrollo: no interpretan información posicional ni tampoco procesan la información de señalización no genética procedente de otras células. En efecto, las células se transforman en ordenadores pasivos. Los entornos citoplasmáticos y embrionarios son variables simplemente insignificantes desde esta extremista perspectiva preformacionista. Como Wolpert (1991) supuso, parafraseando a William Harvey: ex DNA omnia (cf. Mahner \& Bunge, 1997). 


\section{LAS GOMPLEJIDADES DEL DEBATE GONTEMPorÁNEO}

La embriología computacional puede ser considerada como el resultado de una era demasiado entusiasta del pensamiento biológico. Dominada por la genética, la idea era simple: ignorar las células y explicar el desarrollo en términos de expresión genética. No obstante, aún cuando parece complejo poder explicar los procesos epigenéticos observados por Trembley, Driesch y Spemann ignorando totalmente el comportamiento celular, deberíamos tener en mente una interrogante aún más elemental: ¿el preformacionismo es capaz de proporcionar una caracterización molecular causal de tales procesos? En esta última parte del artículo vamos a tratar de responder a esta pregunta.

Las raíces epistémicas del preformacionismo informacional forman parte de una ideología que ha sido muy influyente en biología y que se estructura a través de una visión mecanicista de la biología, una visión reduccionista de la ciencia y una visión "localista" respecto al origen causal del desarrollo. El preformacionismo informacional captura en gran parte esta ideología al atribuir una gran relevancia causal al potencial intrínseco y latente del interior del embrión. Sin embargo, históricamente hablando, la vuelta a Weismann representada por la embriología computacional no ha coincidido con una victoria indiscutible del preformacionismo. Algunos modelos epigenéticos han emergido volviendo a proponer caracterizaciones moleculares del concepto de campo. El debate contemporáneo sobre la oposición entre el mosaico y la regulación, como lo sugieren Lawrence y Levine (cf. 2006, p. R239), debe ir más allá de las oposiciones clásicas que han caracterizado a la historia de la embriología. Al mismo tiempo, el debate entre preformacionismo y epigénesis ha avanzado en muchos aspectos.

En primer lugar, los biólogos del desarrollo han llegado a la conclusión de que muchos factores extra-genéticos son relevantes en la explicación de la ontogenia. El preformacionismo clásico preconizado por Weismann, y elevado por Wolpert y Lewis a su apoteosis, se ha vuelto complejo de defender, ya que ignora el comportamiento de las células y de sus interacciones; algo hoy admitido por parte del mismo Wolpert (cf. 1994). En segundo lugar, los enfoques epigenéticos han abandonado gradualmente las tendencias vitalistas y anti-fisicalistas heredadas por Driesch y Spemann, aceptando progresivamente la necesidad de proporcionar una caracterización molecular de los distintos procesos de regulación del desarrollo observados en la naturaleza. Por lo tanto, los términos de la clásica disputa entre preformacionismo y epigénesis han mutado, y actualmente la discusión converge gradualmente hacia una homogeneización de ambas posturas. De hecho, como mostraremos a continuación a través de algunos ejemplos, ningún biólogo del desarrollo simpatizante de la epigénesis podría ignorar actualmente el papel causal de los genes en el desarrollo, así como ningún biólogo del 
desarrollo de marco preformacionista podría ignorar el papel causal de la interacción y comunicación celular.

A su vez, los términos del debate también se han vuelto más complejos. Primero que todo, la negligencia clásica del preformacionismo frente al fenómeno de comunicación intercelular ha sido abandonada y, por otro lado, el alcance explicativo de los modelos clásicos de señalización celular basados en la difusión de morfógenos (cf. Crick 1970) han sido cuestionados. A su vez, el enfoque clásico preformacionista sobre los determinantes nucleares ha sido cuestionado al redefinirse la noción de determinante extra-genético del desarrollo. Levin (2012) ha propuesto que ciertos fenómenos del desarrollo requieren la postulación de factores extra-genéticos que son, no obstante, preformados de alguna forma en el cuerpo del organismo en desarrollo. Como se deja apreciar, esta posición mezcla una visión epigenética (en su énfasis de ir más allá de los determinantes nucleares) y una preformacionista (en su postulación de un programa de desarrollo). En términos más generales, lo que la práctica de la biología del desarrollo demuestra es que existe una conciencia creciente de que probablemente no existen modelos universales que puedan capturar la variedad de los procesos del desarrollo observados experimentalmente. En consecuencia, vamos a ilustrar a través de algunos ejemplos el contexto actual en que el debate entre preformacionismo y epigénesis se está desarrollando.

De Robertis (2009) piensa que su modelo provee una descripción bioquímica y molecular del "organizador" de Spemann, cuya naturaleza bioquímica no pudo ser identificada en la primera parte del siglo xx. Su modelo, al estilo de Turing, ${ }^{2}$ consiste en una red construida en base a dos centros de auto-regulación, uno activador y otro inhibidor. Estos dos centros de señalización, localizados en el lado ventral y dorsal del embrión en desarrollo, ejercen un control transcripcional recíproco, en el sentido de que para cada acción del lado dorsal, hay una reacción del lado ventral, exhibiendo una propiedad de coordinación sistémica de la actividad celular. Así, el orden se genera como producto relacional, dependiendo del estado de las regiones vecinas, de una dialéctica dorso-ventral. Esta dinámica dorso-ventral resulta de vital importancia para entender el fenómeno de autorregulación. En consecuencia, el efecto organizador no es debido solamente a la acción del lado dorsal, sino también de la reacción del lado ventral, por ejemplo cuando las moléculas del lado ventral compensan la pérdida de los productos del lado dorsal: "por cada acción en el organizador de Spemann hay una reacción en la parte ventral del embrión” (De Robertis, 2009). La introducción del

2 Alan Turing (1952) propuso un modelo matemático para explicar los patrones de formación embrionarios. El modelo trata fundamentalmente de un sistema de sustancias químicas - los morfógenos - que se difunden a través de un tejido. La idea general de su modelo es que la interacción recíproca entre reacciones químicas y la difusión de reactivos puede resultar en la formación de patrones morfológicos y espaciales de manera espontánea. 
concepto de campo se hace natural para explicar la dinámica relacional y comunicacional entre los componentes celulares y moleculares del sistema. Además, como hemos señalado más arriba, la formación del campo requiere de la información de las señalizaciones intercelulares y de las interacciones entre células. En el caso del modelo de $\mathrm{De}$ Robertis, los dos centros de regulación también difunden productos a largas distancias en el embrión para mantener la comunicación en ambos lados de la blástula, demostrando su acción deslocalizada y, aparentemente, no por contacto.

El regreso de la epigénesis con un uso clásico del concepto de campo puede verse en los trabajos de Newman y Bhat, quienes proponen que las células, en un contexto embrionario, actúan en ciertas circunstancias como osciladores bioquímicos. Esto es importante ya que, como ellos afirman: "una propiedad clave de los osciladores es su capacidad de sincronizarse”. Proponen entonces que el fenómeno de sincronía de los osciladores bioquímicos es un proceso físico que posiblemente explicaría la "coordinación celular (...) en un amplio dominio de tejidos, un fenómeno descrito en la literatura embriológica más antigua como un campo morfogenético" (Newman \& Bhat, 2009, p. 699). En términos ontológicos, el campo en este modelo corresponde al efecto del comportamiento oscilatorio sincrónico de las células implicadas. Newman y Bhat (2009) atribuyen este efecto a una causa específica, lo que ellos llaman "módulo de los patrones de desarrollo" o DPM. Esto se define como una categoría especial de genes, los genes "caja de herramientas" (toolkit), que encontramos en el genoma animal del pre-metazoo, y que especifican ciertas moléculas que movilizan algunos procesos físicos específicos, cuya acción en un sustrato biológico particular (como en las células de un embrión vertebrado), produce efectos específicos, tales como la formación de un campo. La referencia al proceso de oscilación (OSC) explicaría la formación de un campo. En términos químicos, OSC consiste en la interacción de moléculas particulares (por ejemplo, Wnt, Notch y Hes), cuyo fenómeno físico se produce a través de una sincronización de la oscilación bioquímica, generando un campo cuando se aplica sobre las células de un embrión vertebrado. El modelo de Newman y Bhat mezcla al parecer las propiedades de auto-organización dentro de una visión sistémica preconizada por Turing, pero añadiendo el encanto de la acción a distancia, conservando el carácter holístico del concepto original de campo. Minelli bautiza este fenómeno como "efecto coro" (2009, p. 119). Teniendo en cuenta que la sincronización celular ocurre a distancia, este modelo también exhibe la naturaleza no local característica de las interacciones celulares que tanto vemos en los enfoques epigenéticos.

Otro modelo, aunque más híbrido, es el de Levin (2012), quien define el campo como la suma de todos los patrones de señales no locales que inciden sobre las células y los grupos de células durante la ontogenia. Levin argumenta bajo tres direcciones distintas. Primero, las señales pueden ser de corto rango y largo rango. Segundo, las 
señales pueden ser genéticas, químicas, eléctricas o mecánicas. Y, por último, las señales pueden acarrear información acerca del patrón presente así como del patrón futuro del organismo. Con el primer punto, Levin se aleja de los modelos tradicionales que operan exclusivamente por contacto y proximidad, como el modelo "source-sink" (cf. Crick, 1970). La idea de una acción a distancia mediante señales es uno de los rasgos definitorios del campo como agente de acción no local. El segundo punto implica que Levin esquiva las restricciones que arrastra el preformacionismo genético o informacional al considerar varios tipos de señales como "codificados" en el campo. La idea central de la tesis de Levin respecto a la morfología es que existe una amplia gama de determinantes potenciales no genéticos - por ejemplo, determinantes mecánicos o bioeléctricos - que son invisibles para las técnicas de perfil molecular contemporáneas, principalmente centradas en las señales genéticas. Por ejemplo, los gradientes que proveen la información posicional para establecer un campo no son sólo químicas o transcripcionales, sino que también de naturaleza eléctrica (voltaje). Así, Levin (cf. 2012, p. 247, 256) propone la interesante tesis de que, además de un código genético, hay por lo menos un código bioeléctrico (por ejemplo, patrones dinámicos de flujo de iones) y posiblemente otros códigos físicos de información codificada. La explicación de porqué las señales llevan información sobre el patrón presente y futuro del organismo es que los campos contienen la información de un pre-patrón, una especie de andamio o plantilla utilizada para crear y mantener la forma del organismo. Este fenómeno es denotado por Levin como “morfología-objetivo' (target morphology). En este sentido la posición de Levin convive con una suerte de preformacionismo.

La razón para postular una morfología-objetivo es que algunos procesos de desarrollo parecen ser explicables sólo si se postula algún tipo de "memoria"; como la llamada "memoria trófica" (cf. Bubenik \& Pavlansky, 1965). En los ciervos, las lesiones sufridas en una posición específica del asta, son "recordadas" por el organismo en el sentido de que el organismo es capaz de producir crecimientos ectópicos (es decir, nuevas púas) en la misma posición en el futuro. La existencia de este fenómeno tiene, de acuerdo con Levin, las siguientes implicaciones: "En primer lugar, la ubicación de las lesiones en los sitios remotos se comunican a las células del cuero cabelludo a una distancia considerable. En segundo lugar, las células en la zona de crecimiento en el cuero cabelludo tienen una memoria espacial que dura al menos varios años" (Levin, 2012 , p. 247). Levin argumenta que la mejor explicación para ese fenómeno es la postulación de una morfología-objetivo:

Una lesión en un lugar específico en una púa puede inducir un cambio físico en el mapa de la estructura en el lugar correspondiente (por ejemplo, un cambio en una red neuronal almacenando la morfología), haciendo que la púa extra sea 
recapitulada en los siguientes años a medida que crecen las astas y a medida que las células ‘consultan' (son controladas por) el mapa (Levin, 2012, p. 24.9).

Levin sugiere que el mapa se almacena neuralmente, a pesar de que los mecanismos mediante los cuales las células y los tejidos son instruidos por el mapa durante la formación del tejido sigan siendo desconocidos. En la opinión de Levin, el campo no debería entenderse únicamente en términos de interacciones celulares o propiedades holísticas; sino que su funcionamiento debería entenderse de manera más amplia, como la acción causal de un mapa: una suerte de plantilla que guía la forma. El concepto de morfología-objetivo evoca en cierta forma el recurso de una pre-forma (la forma se codifica en este "mapa" y se almacena en el organismo en lugar de ser construido gradualmente por un proceso epigenético); y también parece conllevar cierta teleología: ese mapa controla la morfogénesis constriñendo su estado final y los mecanismos que rigen el proceso. En este sentido, hablamos de un pre-patrón global que constriñe la espontaneidad epigenética de la formación de patrones ontogenéticos. Es por esto que el modelo de Levin se perfila como una vía híbrida que incluye elementos preformacionistas y epigenéticos.

Finalmente, es importante remarcar que todas las visiones que hemos visto en este apartado incluyen la idea de campo como una manera de graficar la acción coordinada y conjunta de las células y sus elementos para formar patrones morfológicos complejos. Como lo ha sostenido distintos biólogos del desarrollo (cf. Laubichler \& Wagner, 2001): es el contexto organizacional el que determina el papel causal específico que desempeñan los inter-actores celulares y moleculares en el proceso del desarrollo. La importancia del contexto sobre los determinantes estructurales endógenos también muestra otra de las características de la historia de la embriología y de la biología del desarrollo: la naturaleza cíclica de la disputa entre preformacionismo y epigénesis, cuyas tesis han sabido renovarse frente al paso del tiempo.

\section{Conclusiones}

Nuestra conclusión más general apunta hacia el análisis de la naturaleza de la oposición entre preformacionismo y epigénesis. Se podría argumentar que, como no existe ni un embrión completamente mosaico ni uno completamente regulativo, el desarrollo no corresponde a un proceso totalmente preformacionista ni epigenético. Por lo tanto, la disputa entre las dos posiciones podría confinarse al basurero de la historia de la embriología, dado que ambas posturas son incompletas por sí mismas. Sin embargo, es posible que este argumento se base en una interpretación histórica sesgada. 
De hecho, sólo el preformacionismo se ha caracterizado históricamente como una posición categórica según la cual el desarrollo cae "exclusivamente" sobre los determinantes endógenos (según lo definido), mientras que la epigénesis siempre se ha caracterizado, en oposición al preformacionismo, como la tesis que alega de que "al menos algunos" determinantes son exógenos. Si la oposición se caracteriza de esta manera, sólo el preformacionismo ha sido indudablemente refutado experimentalmente. Lo mismo podría decirse sobre la disputa entre el darwinismo y el lamarckismo con respecto a la naturaleza del proceso de la mutación. Si el primero se caracteriza como la tesis según la cual "todas" las mutaciones son "azarosas" (con respecto a la adaptación), mientras que el segundo, por el contrario, defiende que al menos "algunos" cambios son "dirigidos", (lo que Sarkar llama "lamarckismo débil"), entonces, aunque parezca extraño, el darwinismo mutacional ha sido refutado experimentalmente (cf. Sarkar, 2005, p. 328). Por lo tanto, la evidencia empírica ha sido importante para demostrar que dos interpretaciones influyentes de los procesos vivos (preformacionismo clásico y darwinismo mutacional) son anacrónicos al ser caracterizadas como nociones categóricas. Al igual que el darwinismo mutacional, cuando el preformacionismo y la epigénesis son caracterizadas categóricamente, caen en ficciones biológicas. $\mathrm{Al}$ respecto, la evidencia empírica ha sido fundamental para mostrar que el desarrollo de los organismos de todas las especies es una combinación de factores determinantes endógenos y exógenos. Sin embargo, la disputa persiste por al menos dos razones.

La primera tiene que ver con la escasez de evidencia empírica. Las posturas preformacionistas que han privilegiado los factores de transcripción o que han postulado conceptos como el morfología-objetivo, así como los planteamientos epigenéticos que han privilegiado las interacciones celulares y la comunicación intercelular, deberían ser capaces de explicar la naturaleza de los fenómenos tales como la regeneración de partes (observado por Trembley), la respuesta a una lesión (es decir, la capacidad de un tejido para responder a la lesión observada por Bubenik), el fenómeno de escala embrionaria (es decir, el proceso de reajuste que resulta en un adulto viable de menor tamaño observado por Driesch), la modularidad de la organización (es decir, la capacidad de un tejido para generar un fenotipo específico en un contexto de desarrollo diferente, observado por Mangold y Spemann), etc. La biología del desarrollo sin duda ha hecho avances teóricos en este sentido, por ejemplo, la hipótesis de la célula fundadora (es decir, la célula que comienza a secretar un morfógeno que desencadena una respuesta morfogenética específica) ha sido complementada por el modelo de autoorganización de Turing: "Las 'células del organizador' no tienen que estar predeterminadas (aunque en ciertos embriones, determinantes maternos influenciarán su localización); una vez establecidas, los gradientes de difusión que configuran tendrán consecuencias globales de modelado" (Müller \& Newman, 2003, p 228). Es posible que 
los procesos de señalización celular sean más relevantes de lo estimado originalmente por Wolpert (1969) y Crick (1970) (quienes calcularon que la mayoría de los campos embrionarios implican distancias máximas de 100 células). Nuevos modelos de interacción celular, como los expuestos en la sección 4, van más allá de los modelos de difusión, al postular la comunicación de larga distancia entre las células a través de una variedad de medios (por ejemplo, quimiotaxis, "efecto coro", oscilación sincronizada). A su vez, la morfología-objetivo amplía la concepción estándar de la herencia y el enfoque tradicional de la genética del desarrollo de los factores de transcripción. No obstante, a pesar de los avances teóricos, se necesita trabajo experimental para apoyar todos estos modelos conceptuales. Es por esto que sugerimos en primera instancia que la disputa entre epigénesis y preformacionismo persiste por razones empíricas, más específicamente, por su ausencia.

La segunda razón, y probablemente la más importante, que explica la persistencia del debate es que el preformacionismo y la epigénesis intentan explicar el desarrollo a través de diferentes concepciones causales. En efecto, como ya hemos indicado en nuestro análisis, un lado de la discusión abraza la postulación de un plan preformado, un principio determinativo que rige el desarrollo. En este sentido, también el concepto morfología-objetivo de Levin es preformacionista (la forma se codifica en el mapa y se almacena en el organismo, en lugar de ser construido gradualmente epigenéticamente). Una de las raíces fundamentales de la oposición preformaciónismo-epigénesis se refiere a la localización y a la naturaleza física de este principio de orden estructural. Los enfoques preformacionistas han localizado tradicionalmente este principio en alguna parte del embrión fertilizado. Sin embargo Levin considera los principios de orden (como la morfología-objetivo) no locales por excelencia, dado que las fuerzas causales que inciden en un componente del sistema no son sólo locales. La verdadera ruptura con la tradición preformacionista sería considerar viable una teoría del desarrollo que no apele a ningún principio determinante preformado. Turing (1952) hizo una contribución en esta dirección. En la visión causal preformacionista de la embriogénesis, el agente causal que inicia el proceso morfogenético corresponde a un principio que debe pre-existir y gobernar este proceso. Sin embargo, el modelo de reacción y difusión de Turing provee una conceptualización de cómo una estructura puede surgir de un material homogéneo debido a las propiedades de auto-organización sin necesidad de un plan central predeterminado. El modelo funciona sobre un contexto embrionario continuo, homogéneo y simétrico, cuyo desequilibrio, a causa de perturbaciones aleatorias, gatilla una serie de procesos en el sistema que resultan en el desarrollo de patrones estructurales espontáneos. En el mismo sentido, Goodwin argumenta que: "Hay algo en la organización dinámica interna de un huevo que hace su simetría esférica inestable, por lo que cualquier perturbación, una fluctuación interna 
de iones, por ejemplo, o un estímulo externo, lo va a activar" (1994, p. 44). En este sentido, el modelo de Turing reivindica una posible vía epigenética pura.

Otra importante oposición de relevancia causal se refiere al papel de las moléculas, células y tejidos en desarrollo. El problema está bien ilustrado por Levin.

En general se supone (...) que el mejor camino para la comprensión de la generación de la forma es mediante la disección mecanicista de las normas que rigen el comportamiento de una sola célula. Así, muchos esperan que a través de la biología de sistemas (...) algún día entenderemos cómo los comportamientos de las células se suman a la construcción dinámica y al complejo mantenimiento de una morfología de 3 dimensiones (Levin, 2012, p. 24,8).

Sin embargo, si efectivamente existe una morfología-objetivo, entonces el entender la actividad a nivel celular no es el contexto de análisis más adecuado para comprender la morfogénesis: un contexto de análisis causal más global es necesario. Desde una perspectiva holista, los análisis de los procesos del desarrollo en términos moleculares - como los enfoques preformacionistas contemporáneos que se centran en los determinantes genéticos y en la transcripción - están condenados a fallar. A su vez, lo mismo puede decirse de los análisis celulares epigenéticos, cuyos enfoques están centrados en los comportamientos de grupos de células junto a sus capacidades de comunicación. En consecuencia, a pesar de que la dialéctica entre preformacionismo y epigénesis ha evolucionado a través del tiempo y ha sabido evolucionar al ritmo de los avances experimentales de la biología del desarrollo, creemos que estas inquietudes metafísicas sobre la naturaleza causal del fenómeno del desarrollo permanecerán abiertas durante mucho tiempo más.

Davide Vegchi

Centro de Filosofia das Ciências, Faculdade de Ciências, Universidade de Lisboa, Portugal. davide.s.vecchi@gmail.com

Isaac HERNÁNDEZ

École doctoraleALLPH@, Laboratoire ERRAPHIS, Université Tolouse Jean Jaurès, France. hernandez.isaac@gmail.com

Epigenesis and pre-formationism: radiography of an inconclusive antinomy 


\begin{abstract}
The process of development of the embryo has inspired philosophical speculation since the advent of Western thought. Since the time of Aristotle two antithetical conceptual models have traditionally been used to understand embryogenesis: either form or structure is preformed in the embryo or it is newly formed with each generation. Our aim in this article is to show that the contrast between the preformationist and epigenetic positions persists despite the formidable theoretical and experimental advances of contemporary developmental biology. Pre-formationism and epigenesis have constantly refined their positions in the course of history in order to answer the conceptual challenges of each epoch. This process of continuous transformation has resulted in a partial convergence of the two positions. However, we shall argue that, despite the partial successes of this process of continuous convergence, one of the most fundamental antinomies in biology persists.
\end{abstract}

KEYwords • Embryo. Pre-formationism. Epigenesis. Determinant. Morphogenetic field. Morphogen. Regulation.

\title{
REFERENGIAS BIBLIOGRÁFIGAS
}

Amsterdamska, O. From pneumonia to DNA: the research career of Oswald T. Avery. Historical Studies in the Physical and Biological Sciences, 24, p. 1-4, $0,1993$.

Amundson, R. The changing role of the embryo in evolutionary thought. Cambridge: Cambridge University Press, 2005 .

Boveri, T. Die Potenzen der Ascaris-Blastomeren bei abgeänderter Furchung, zugleich ein Beitrag zur Frage qualitativ-ungleicher Chromosomen-Teilung. Festschrift für Richard Hertwig. Jena: Gustav Fischer, 1910. v. 3 .

Bubenik, A. B. \& Pavlansky, R. Trophic responses to trauma in growing antlers. Journal of Experimental Zoology, 159, p. 289-3०2, 1965 .

CRICK, F. Diffusion in embryogenesis. Nature, 225, p. 4,20-2, 1970.

De Robertis, E. Spemann's organizer and the self-regulation of embryonic fields. Mechanisms of Development, 126, p. 925-41, 2009.

Driesch, H. The history and theory of vitalism. London: McMillan, 1914.

Dupont, J.-C. L'embryologie: histoires et perspectives. In: Kupiec, J. J. (Ed). La vie et alors? Débats passionnés d'hier et d'aujourd'hui. Paris: Belin, 2013. p. 237-67.

FALK, R. The gene in search of an identity. Human Genetics, 68, p. 195-204, 1984.

Gilbert, S. F. et al. Resynthesizing evolutionary and developmental biology. Developmental Biology, 173 , p. $357^{-} 7^{2}, 1996$.

Goodwin, B. How the leopard changed its spots: the evolution of complexity. New York: Charles Scribner's Sons, 1994 .

Gurwitsch, V. A. Über Determination, Normierung und Zufall in der Ontogenese. W. Roux' Archiv für Entwicklungsmechanik, 3०, p. 133-93, 1910.

Hamburger, V. Hans Spemann on vitalism in biology. Journal of the History of Biology, 32, p. 231-43, 1999.

HaRAWAY, D.J. Crystals, fabrics, and fields: metaphors of organicism in twentieth-century developmental biology. New Haven: Yale University Press, 1976.

Hernández, I. Sobre el concepto de organismo: una mirada hacia los fundamentos de la biología. Santiago, 2012. Tese (Doutorado em Filosofia). Universidad de Santiago de Chile.

Huxley, J. \& de Beer, G. R. The elements of experimental embryology. Cambridge: Cambridge University Press, 1934 . 
EPIGÉNESIS Y PREFORMAGIONISMO: RADIOGRAFÍA DE UNA ANTINOMÍA INGONGLUSA

KeLLER, E. F. Making sense of life: explaining biological development with models, metaphors and machines. Cambridge; Harvard University Press, 2002.

Kupiec, J. J. (Ed.). La vie et alors? Débats passionnés d'hier et d'aujourd'hui. Paris: Belin, 2013.

Laubichler, M. \& Wagner, G. P. How molecular is molecular developmental biology? A reply to Alex Rosenberg's reductionism redux: computing the embryo. Biology and Philosophy, 16, 53-68, 2001.

Lawrence, P. A. \& Levine, M. Mosaic and regulative development: two faces of one coin. Current Biology, 16, p. R236-39, 2006.

LenOIR, T. The strategy of life: teleology and mechanics in nineteenth-century german biology. Dordrecht: The University of Chicago Press, 1989.

Levin, M. Morphogenetic fields in embryogenesis, regeneration, and cancer: non-local control of complex patterning. BioSystems 109, p. 243-61, 2012.

Mahner, M. \& Bunge, M. Foundations of biophilosophy. Berlin: Springer, 1997 .

Maienschein, J. Epigenesis and preformationism. Stanford Encyclopedia of Philosophy, 2005. Disponible en: <http://plato.stanford.edu/entries/epigenesis/>. Acceso en: $3 \circ$ jun. 2015.

Minelli, A. Perspectives in animal phylogeny and evolution. Oxford: Oxford University Press, 2009.

Minelli, A. \& Pradeu, T. (Ed.). Towards a theory of development. Oxford: Oxford University Press, 2014.

Morange, M. A history of molecular biology. Cambridge: Harvard University Press, 1998.

Müller, G. B. \& Newman, S. A. Origination of organismal form: beyond the gene in developmental and evolutionary biology. Cambridge: The MIT Press, 2003.

Newman, S. A. \& Bhat, R. Dynamical patterning modules. International Journal of Developmental Biology, $5^{3,}$, p. 693-7०5, 2009 .

Norro, J. J. G. Las imagenes biológicas de la Crítica de la razón pura. In: Terued, P. J. (Ed.). Kant y las ciencias. Madrid: Biblioteca Nueva, 2011. p. 165-84.

Rosenberg, A. Reductionism redux: computing the embryo. Biology and Philosophy, 12, p. 445-70, 1997.

Rотн, S. Mathematics and biology: a kantian view on the history of pattern formation theory. Development Genes and Evolution, 221, 5-6, p. 255-79, 2011.

SAPP, J. Genesis: the evolution of biology. New York: Oxford University Press, 2003.

SARKAR, S. Molecular models of life. Cambridge: The MIT Press, 2005.

Schrodinger, E. What is life? Cambridge: Cambridge University Press, 1944.

Spemann, H. Embryonic development and induction. New Haven: Yale University Press, 1938.

Teruel, P. J. (Ed.). Kant y las ciencias. Madrid: Biblioteca Nueva, 2011.

Turing, A. M. The chemical basis of morphogenesis. Philosophical Transactions of the Royal Society of London B, 237, p. $37^{-} 7^{2}, 1952$.

Vegchi, D. \& Hernandez, I. The epistemological resilience of the concept of morphogenetic field. In: Minelli, A. \& Pradeu, T. (Ed.). Towards a theory of development. Oxford: Oxford University Press, 2014. p. 79-94.

Watson, J. \& CRIck, F. Genetical implications of the structure of deoxyribonucleic acid. Nature, 171, p. $964,-7,195^{3}$.

Weismann, A. The germ plasm. New York: Charles Scribners, 1893.

Wolpert, L. Positional information and the spatial pattern of cellular differentiation. Journal of Theoretical Biology, 25, p. 1-47, 1969 .

. Positional information and pattern formation. Current Topics in Developmental Biology, 6, p. 183-

224, 1971.

. Positional information revisited. Development, Supplement, p. 3-12, 1989.

The triumph of the embryo. Oxford: Oxford University Press, 1991.

Do we understand development? Science, 266, p. 571-2, 1994.

Wolpert, L. \& Lewis, L. J. Towards a theory of development. Federation Proceedings, 34, p. 14-20, 1975. 